J. DUSHANOVA ${ }^{1}$ and D. MITOV ${ }^{1}$

\title{
EFFECT OF THE ORIENTATION DIFFERENCE ON COMPONENTS OF VISUAL EVENT-RELATED POTENTIALS
}

\author{
Received November 11, 2012.
}

Changes in the components of visual event-related potentials (VERPs) depending on the difficulty of the identification counting tasks ("coarse" and "fine") were studied in healthy humans. The basic finding is that much greater changes in the VERPs waves were observed within a 5 to $15 \mathrm{deg}$ range than those within the range of 15 to $90 \mathrm{deg}$. The amplitude of the second sensory component (P2), the latencies of both sensory components, and that of the second cognitive one increased with increase in the task difficulty, while the amplitudes of both cognitive components N2/P3 decreased. Additionally, small changes in the task difficulty affected the attentional effort and modulated the N1 amplitude and P2 latency. These VERP changes are considered an electrophysiological correlate of the psychophysical data when the "label" of an activated orientation-selective channel is sufficient for "coarse" discrimination, and an additional computational process comparing the responses of the activated channels makes discrimination possible in "fine" discrimination.

Keywords: sinusoidal gratings, orientation identification, visual ERPs (VERPs), sensorymental task.

\section{INTRODUCTION}

In a number of reports, the factors influencing visual event-related potential (VERP) components N1, P2, N2, and P3 were pointed out. One of these factors for the $\mathrm{N} 1$ component is the type of the task, namely detection or identification $[1,2]$. The N1 discrimination effect is observed even when no motor response is required, and this effect is present for both color and form discriminations [2]. Moreover, this discrimination-related effect is equally large for easy and difficult discrimination tasks. The effect is not proportional to the degree of the perceptual load. The P2 VERP component is also differentially affected by task demands. As is known, P2 requires selective attention to different features, with the topographic prevalence over a central line in the orientation and location tasks extending further to the posterior side than the response elicited under color discrimination conditions [1]. Two selective stages, early selection in high-load tasks and late selection in low-load tasks, determine which stimulus is included in or excluded from the attentional focus [3]. The P2 attention effect

\footnotetext{
Institute of Neurobiology, Bulgarian Academy of Sciences, Sofia, Bulgaria. Correspondence should be addressed to J. Dushanova (e-mail:juliana@bio.bas.bg).
}

is modulated by voluntary attentional allocation between competing conditions $[4,5]$. The P2 wave can also be influenced by variations in the perceptual loading. More precisely, the effect of P2 modulation is termed N2 (in particular, its N2pc subcomponent), which has been defined as a negative deflection in the P2 component and is typically inspected at posterior scalp sites. The N2pc wave is considered a response to focusing attention on the features of a target stimulus (like color) and ignoring distracters [1]. The nature of the P3 wave is affected by the appearance of unexpected task-irrelevant stimuli within an attended stimulus train, the target probability [5], as well as the degree of effort devoted by the subject to the task [6]. It is important for practical applications to look for electrophysiological evidence in support of "coarse"/"fine" identification in the visual system.

In our study, we examined the effect of orientation difference of sinusoidal gratings on the amplitude and latency of VERP waves in mental tasks, such as counting (i.e., with causing a substantial cognitive load). The occurrence of the mental task should produce additive effects on the wave components, differing from binary motor conditions when orientation difference was changed within the ranges 5 to $15 \mathrm{deg}$ or 15 to $90 \mathrm{deg}$. 


\section{METHODS}

Observers. The observers (11 women and 9 men, $31 \pm 7$ years) were with a normal or corrected-to-normal visual acuity. They had no known ophthalmological or neurological diseases. The subjects were instructed to visually fixate the center of the screen. The handedness was assessed by a questionnaire adapted from the Edinburgh Handedness Inventory (Oldfield, 1971).

Stimuli. Stimuli were sinusoidal gratings with a spatial frequency of $2.9 \mathrm{deg}^{-1}$, presented in a circular Gaussian window with the spatial constant of $0.483 \mathrm{deg}$ and contrast of 0.05 . They were presented for $100 \mathrm{msec}$ in the center of the visual field. Stimulus orientation was $90,85,75$, or 0 deg.

Apparatus. The stimuli were generated by a computer as 12-bit signals and were displayed on the screen of a monochrome monitor $(640 \times 480$ pixels, frame rate $60 \mathrm{~Hz}$ ). The viewing distance was $1.14 \mathrm{~m}$, and the mean luminance was $50 \mathrm{~cd} / \mathrm{m}^{2}$; it was not changed by stimulus onset and offset.

Procedure. In each trial, the stimulus orientation varied randomly between two possible values -90 and $0 \mathrm{deg}, 90$ and $75 \mathrm{deg}$, as well as 90 and $85 \mathrm{deg}$. Therefore, the difference between orientations was 90,15 , and $5 \mathrm{deg}$. The subjects performed a sensorymental task. They had to count the number of stimuli with orientation different from vertical (90 deg) when the stimulus had an oblique or a horizontal orientation. The interval between trials varied randomly within the range of 2.5 to $3.5 \mathrm{sec}$. Each block contained 100 trials. The EEG was recorded from 12 leads, Fz, $\mathrm{Cz}, \mathrm{Pz}, \mathrm{Oz}, \mathrm{C} 3, \mathrm{C} 4, \mathrm{~T} 3, \mathrm{~T} 4, \mathrm{P} 3, \mathrm{P} 4, \mathrm{O} 1$, and $\mathrm{O} 2$ (10/20 system), with reference to both processi mastoidei and a ground electrode placed on the forehead. The oculogram (EOG) was recorded via electrodes placed above and below the lateral cantus of the left eye (for detection of eye movements and blink artifacts). EEG and EOG data were recorded using a Nihon Kohden EEG-4314F (Japan; cut-off frequencies 0.3 and $70 \mathrm{~Hz}$ ) together with markers of the stimulus onset, as well as those of motor responses. The signals were digitized at a rate of $500 \mathrm{sec}^{-1}$ and recorded on a hard disk for offline analysis. The length of EEG segments was chosen to cover 500-msec pre-stimulus and 1,000-msec poststimulus intervals. Only artifact-free VERP records were processed. Extraction of the baseline correction corresponded to the 300 -msec-long pre-stimulus time period (i.e., -400 to $-100 \mathrm{msec}$ ). The parameters of VERP waves were computed relatively to the corrected baseline. Later on, the signals were verified to have a signal-to-noise ratio (SNR) above mean 1.1. The SNRs were calculated using the following formula: $\mathrm{SNR}=\mathrm{A} / 2 \cdot$ s.d. $_{\text {noise}}$, where the amplitude $\mathrm{A}$ is the peak-to-peak voltage of the mean VERP, and s.d. ${ }_{\text {noise }}$ is the noise standard deviation [7]. The noise $\varepsilon$ was obtained by subtracting the mean from each individual VERP. In other words, for a given single electrode, $\varepsilon$ is just the collection of residuals when the mean ERP is subtracted from each individual VERP, and s.d. ${ }_{\text {noise }}$ is the standard deviation over this collection. The mean interval across stimulus/task combination for each wave was $\mathrm{N} 1$ ( 80 and $140 \mathrm{msec}$ ), P2 (130 and $200 \mathrm{msec}$ ), N2 (190 and $298 \mathrm{msec}$ ), and P3 (290 and $550 \mathrm{msec}$ ). The statistical differences between the corresponding VERP components at orientation differences $90 / 15,90 / 5$, and $15 / 5$ deg were obtained by means of the Kruskal-Wallis test for paired comparison of the scalp leads between stimulus datasets.

\section{RESULTS}

Performance Accuracy. The performance accuracy of the counting at the smallest orientation difference $5 \mathrm{deg}$ was the worse (mean \pm s.e.m., $91.12 \pm 2.03 \%$ ) in comparison with the accuracy at the medium $15 \mathrm{deg}$ $(96.97 \pm 0.76 \%)$ and the highest $90 \mathrm{deg}(95.76 \pm$ $\pm 2.10 \%$ ) orientation difference. Pair comparison of the performance accuracy observed at different orientation differences showed the following results: $F_{(5 \mathrm{deg} \text { and } 15 \mathrm{deg})}$ $(1,39)=5.09, P_{(5 \mathrm{deg} \text { and } 15 \mathrm{deg})}=0.024 ; F_{(5 \mathrm{deg} \text { and } 90 \mathrm{deg})}$ $(1,39)=6.72, P_{(5 \mathrm{deg} \text { and } 90 \mathrm{deg})}=0.0095, F_{(15 \mathrm{deg} \text { and } 90 \mathrm{deg})}$ $(1,39)=0.35, P_{(15 \mathrm{deg} \text { and } 90 \mathrm{deg})}=0.55$.

Orientation Difference-Related Effect on the VERP Waves. The first negative VERP wave N1 showed an amplitude scalp distribution with a maximal value at the temporal lobe and a minimal value at the occipital lobe. This was observed at the orientation differences of 90 and $5 \mathrm{deg}$ (Fig. 1A, first row), as at the medium orientation difference $(15 \mathrm{deg})$. The maximal values of $\mathrm{N} 1$ were observed over the central scalp positions (Fig. 1A, first row).

The amplitude of the $\mathrm{N} 1$ component first increased with decrease in the orientation difference from 90 to $15 \mathrm{deg}$ and then decreased with further decrease in the above difference. This was not in the case at two scalp positions, T3 and T4, where the amplitude of the N1 component did not depend on the orientation difference. The latency of the N1 component (Fig. 1B, first row) did not demonstrate clear extremes at any scalp positions, as it became longer with decrease in 
$A$
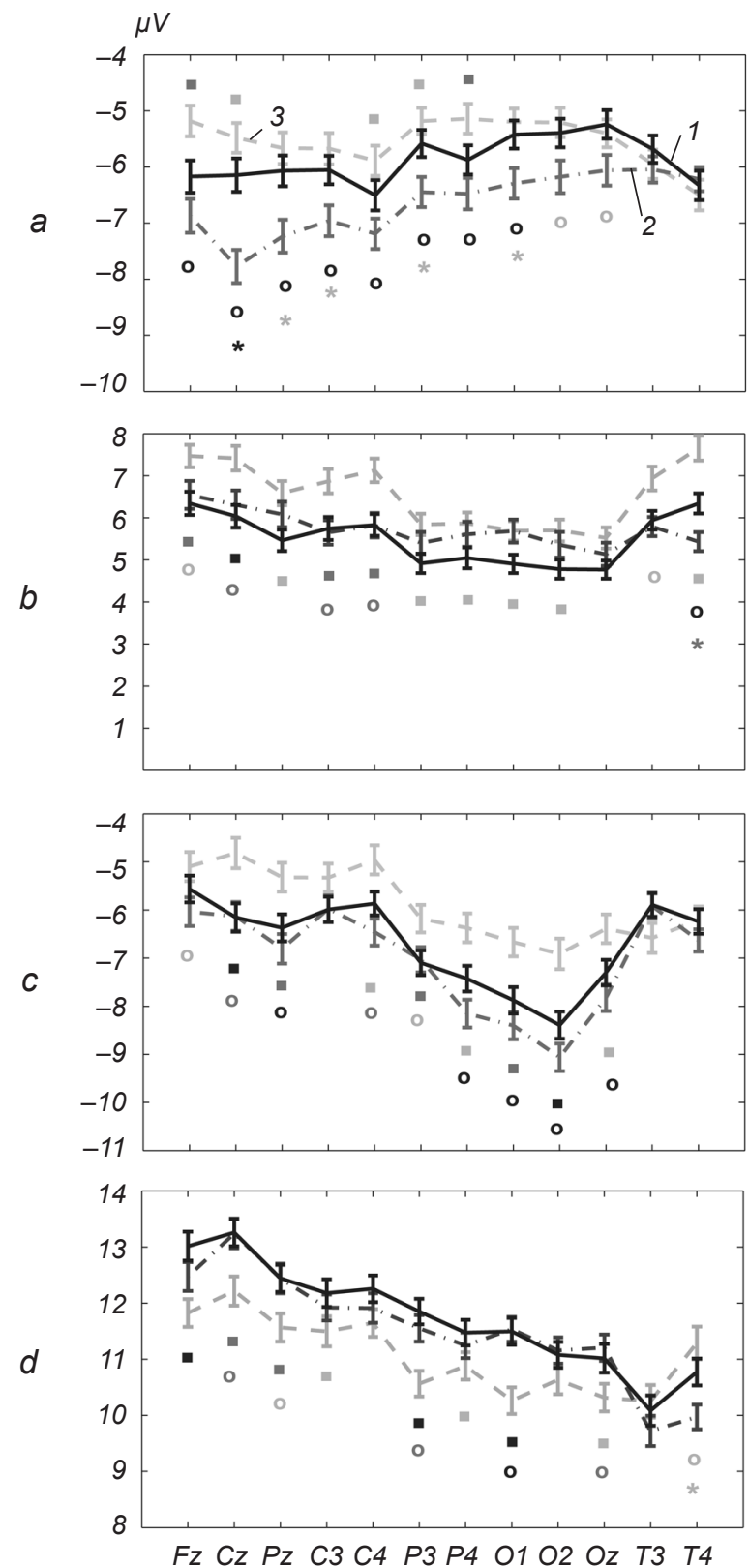

$B$
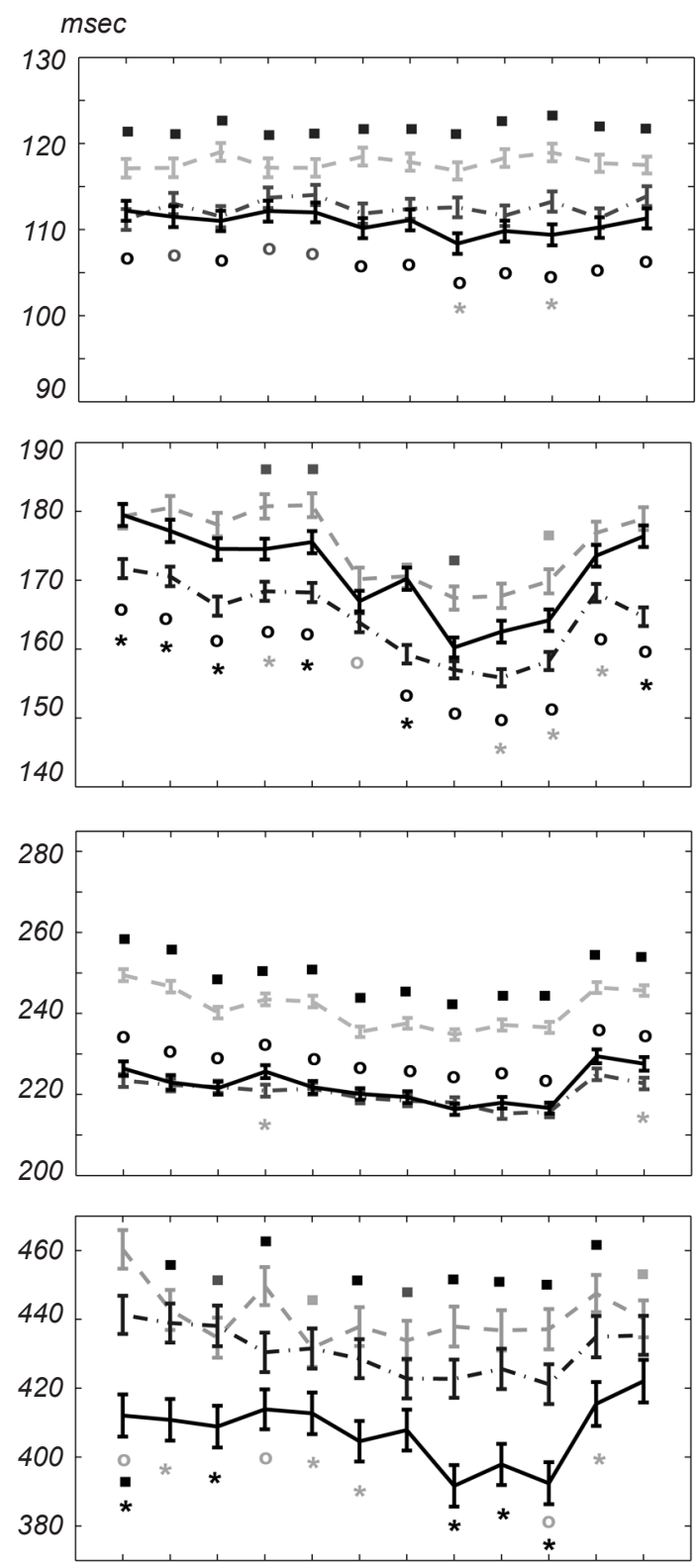

Fz Cz Pz C3 C4 P3 P4 O1 O2 Oz T3 T4

F i g. 1. Scalp distributions and statistical comparisons of the amplitudes of visual event-related potential (VERP) waves (N1, P2, N2, and P3, a-d, respectively). A and B) Amplitudes ( $\mathrm{mV}$ ) and latencies (msec) of VERP components recorded at three orientation differences (curves 1-3 correspond to 90, 15, and $5 \mathrm{deg}$, respectively). All parameters of the VERP components presented on this figure are those of the responses to vertical gratings only. Vertical bars represent 95\% confidence intervals. Circles, squares, and asterisks indicate results of different pair comparisons: 5 deg difference with that of $15 \mathrm{deg}$ (circles), 5 deg difference with that of 90 deg (squares), and 15 deg difference with that of $90 \mathrm{deg}$ (asterisks). The colors of these symbols correspond to different critical values of the significance: black, $\mathrm{P}<0.001$, gray, $\mathrm{P}<0.01$, and light gray, $\mathrm{P}<0.05$. Horizontal scale) Scalp leads according to the $10 / 20$ international system.

P и с. 1. Топографічний розподіл та статистичні порівняння амплітуд хвиль візуальних пов'язаних 3 подією потенціалів (N1, Р2, N2 та Р3, $a-d$ відповідно). 
the orientation differences. However, the prolongation of the N1 latency was statistically significant within the orientation difference range of 5 to $15 \mathrm{deg}$ only at most electrode positions, with the exceptions at $\mathrm{O} 1$ and $\mathrm{Oz}$, where the orientation difference influenced the N1 latency within all the values studied (5 to $90 \mathrm{deg}$ ).

The P2 wave demonstrated the maximal amplitude over the fronto-central and sensorimotor areas at all orientation differences. The maximal P2 amplitude was also observed over the temporal area at the greatest $(90 \mathrm{deg})$ and the smallest (5 deg) orientation differences. The minimal values of the P2 amplitude were observed over the occipital and parietal areas, as well as over the temporal area, at the medium orientation difference (15 deg; Fig. 1A, second row, black and gray). The amplitude of the P2 component increased with decrease in the orientation difference, as this effect was statistically significant in the frontal areas within the range of 5 to $15 \mathrm{deg}$ only; there are no asterisks in Fig. 1B, second row, with the exception at T4 only, which indicates statistically significant changes caused by the orientation difference variation within the range of 90 to $15 \mathrm{deg}$. Similarly to the amplitude distribution, the P2 latency also demonstrated maximal values over the fronto-central, sensorimotor, and temporal areas, and minimal values were observed over the occipital lobe (Fig. 1B, second row). The P2 latency first decreased with decrease in the orientation difference from 90 to $15 \mathrm{deg}$ and then increased with further decrease in this difference. Changes in the P2 latency were statistically significant within the entire range of orientation differences studied (5 to $90 \mathrm{deg}$ ) at most scalp positions, with exceptions at $\mathrm{P} 3$ and $\mathrm{O} 1$ leads, where changes in the P2 latency were observed within the 5 to 15 deg range.

The N2 wave showed a maximal amplitude over the occipital lobe and a minimal amplitude over the central fronto-parietal, sensorimotor, and temporal cortex areas. This was better expressed at the greatest (90 deg) and the medium (15 deg) orientation differences, and, to a lesser extent, at the smallest (5 deg) difference (Fig. 1A, third row). The N2 amplitude decreased with decrease in the orientation difference, mainly within the range of 5 to $15 \mathrm{deg}$. This effect, however, was not observed in the temporal lobe, where the N2 amplitude was not influenced by the orientation difference. The latency of the N2 component demonstrated maximal values over the fronto-central, sensorimotor, and temporal areas, and a minimal value over the occipital lobe. The N2 latency became longer with decrease in the orientation difference, but this effect was statistically significant only within the 5 to $15 \mathrm{deg}$ range, with two exceptions (C3 and T4) where the effect of the orientation difference was statistically significant within the entire studied range, 5 to $90 \mathrm{deg}$ (Fig. 1B, third row).

The amplitude scalp distribution of the P3 wave demonstrated a maximum in the central frontal areas $(\mathrm{Fz}$ and $\mathrm{Cz})$ for all three orientation differences (Fig. 1A, fourth row). The P3 amplitude increased as the orientation difference increased, and this increase was statistically significant within the range of 5 to $15 \mathrm{deg}$ for scalp positions $\mathrm{Cz}, \mathrm{Pz}, \mathrm{P} 3, \mathrm{O} 1, \mathrm{Oz}$, and $\mathrm{T} 4$ and within the range of 15 to $90 \mathrm{deg}$ for position T4. The P3 latency demonstrated a small maximum at frontal leads, and this effect was more evident at smallest orientation differences. The latency of the P3 component lengthened with decrease in the orientation difference within the entire range of orientation difference variation (5 to $90 \mathrm{deg}$; Fig. 1B, fourth row).

\section{DISCUSSION}

An increase in task difficulty (decrease in the orientation difference from 15 to $5 \mathrm{deg}$ ) resulted in the reduction of the N1 amplitude in VERPs recorded in the sensory-mental task. At the same time, the N1 amplitude increased with decrease in the orientation difference within the range of 90 to $15 \mathrm{deg}$ [7]. It might be suggested that counting is a process generating a different type of brain activity that interferes with activity involved in an identification process. The fact that the oblique grating could not be adequately identified and counted at a small orientation difference suggests that the insufficient discrimination resulted from either exhaustion of the perceptual or cognitive capacity (which gives the ability to count accurately) or the attention that can be set to block irrelevant inputs from selected processing. The effect of task difficulty can be considered an effect of attentional effort modulation [8-10]. Modulation of the attentional effort related to transition of the orientation difference (15 deg) between easy (90 deg) and difficult (5 deg) orientation tasks can be explained by the assumption that the first sensory component corresponds to more than one active attentional process, such as an "N1 discrimination effect" and an "N1 reorienting effect" [11]. The former N1 attention effect may involve a discriminative process restricted to an oriented area 
in the sensory space and may reflect an enhanced perceptual processing [11]. The N1 "reorienting effect" represents an enhanced negativity reflecting an attentional switch from one orientation to another [4]. The N1 discrimination effect can only be influenced by mental fatigue that decreases attention [12]. An increase in task difficulty prolongs the latency of the N1 wave because the process of counting includes an increased level of difficulty when a subject estimates the number of stimuli with small orientations, keeps track of the running sum, and retrieves and generates the count-words. In addition, demands are executive processes in both memory and attention (to keep track of which gratings have already been counted and ensure the process of continuing in an effective way over time). This provides evidence for a more generalized change in the attentional modulation and interaction of selective attention with working memory.

The next VERP wave P2 demonstrated changes in the amplitude predominantly within the orientation difference range of 5 to $15 \mathrm{deg}$. The amplitude of the P2 wave increased with decrease in the orientation difference. With respect to the anterior P2 waves, it was found that their amplitude increased with increase in task difficulty within the 5-15 deg range. Similarly to the case of the N1 amplitude, the task difficulty within the 15-5 deg orientation difference prolonged the P2 latency, while it reduced this latency within the orientation difference range of 90-15 deg because small changes in the task difficulty affected the attentional effort and modulated the parameters of the P2/N1 complex [9, 10]. Visual attention has been found to be an effort-extensive process, which depends on the nature of the task [3-5]. Components like $\mathrm{P} 2 / \mathrm{N} 1$ have demonstrated modulation due to attending to features like orientation or color and can actually contribute to the measurement of cognitive processes in the visual system [1, 10]. The differences in the direction of the $\mathrm{P} 2$ effect found in studies with different types of task may indicate that the P2 reflects activation of different visual pathways, namely the pathway processing target- and direction-related information and the pathway processing information about the movement.

The amplitude of the next negative VERP wave, N2, decreased with decrease in the orientation difference. Similarly to the influence of the task on the N1 latency, an increase in the task difficulty resulted in prolongation of the N2 latency. The anterior N2 component is sensitive to orientation discrimination in both sensory/mental and motor experiments [7].
The posterior N2 amplitude was much more prominent than that of the anterior N2 in the counting task. The maximal amplitude was observed in the occipital sites for easy discrimination. These posterior N2 differences elicited were influenced by both the experimental context and the effect of the target status, as arising from deviation in the task difficulty. The majority of observed N2-related effects could be attributed to some processes, such as response inhibition, response conflict, and error monitoring [13]. The instructions requested only accuracy in silent counting. The N2 component included also a related activity in unsuccessful trials. The error-related negativity may reflect the adjustment of short- and long-term response strategies after a mistake, a compensatory response, and a slower response in the subsequent trial [13].

The amplitude of the endogenous (ERP) P3 wave decreased with increase in the task difficulty. Correlations between decrease in the orientation difference and the amplitude in a cover-response task were consistent with the viewpoint that more difficult tasks are associated with less attention to the targets $[10,14]$. The flexible strategies of distributing attention were evidently no longer available, and the P3 wave was rather a measure of allocation of attentional resources in the sensory-mental study [15]. When subjects performed the counting task, additional demands are imposed on both memory and executive processes (to keep track of which gratings have already been counted and ensure the process of continuing in an effective way over time). The insufficient discrimination resulted from exhaustion of either perceptual/cognitive capacity or the attention and selected processing. Therefore, the attentional fatigue reflected a reduction of the P3 amplitude with increase in the task difficulty. The latency of the P3 component is believed to correspond to the rate of cognitive processing [13]. The P3 latency increased with decrease in the orientation difference in counting tasks. This was associated with the task difficulty and looked like a measure of the duration of stimulus evaluation processes (encoding, recognition, and classification) independent of response selection and execution $[16,17]$.

The basic result of our experiments is the fact that much greater changes in the VERP waves are observed within the range of 5 to $15 \mathrm{deg}$ than those within the range of 15 to $90 \mathrm{deg}$. Small changes in the attentional effort can, however, also modulate the parameters of some waves within the orientation difference from 15 to $90 \mathrm{deg}$ in the transition zone between easy and 
difficult tasks (orientation difference $15 \mathrm{deg}$ ) [9]. The relationship between the response conflict and error detection remains a contentious issue. In summary, under conditions of our experiments, stimuli activated either independent orientation-selective mechanisms (at 15 and 90 deg orientation differences) or mechanisms with overlapping tuning curves (at a $5 \mathrm{deg}$ orientation difference) [7, 18-20].

All experiments reported in this paper were carried out under an approved protocol from the Ethics Committee of the Institute of Neurobiology (BAS), and all subjects gave their written informed consent according to the Helsinki declaration.

The authors, J. Dushanova and D. Mitov, declare that they have no potential competing interests or commercial relationship, including grants, honoraria, speaker's lists, significant ownership, and support from pharmaceutical or other companies such as manufactures of equipment and diagnostic or other laboratories whose products are directly or indirectly involved or affected by the article.

The authors acknowledge support from the National Science Fund (NSF) of Bulgaria (project 0475/2008).

\section{Ю. Душанова ${ }^{1}$, Д. Мітов}

\section{ВПЛИВ ВІДМІННОСТЕЙ ОРІЄНТАЦІЇ НА КОМПОНЕН- ТИ ЗОРОВИХ ПОВ' ЯЗАНИХ ІЗ ПОДІЕЮ ПОТЕНЦІАЛІВ}

\author{
${ }^{1}$ Інститут нейробіології Болгарської Академії наук, Софія \\ (Болгарія). \\ P е 3 ю м е
}

У здорових суб'єктів досліджувалися зміни компонентів візуальних пов'язаних із подією потенціалів (ВППП), залежні від труднощів ідентифікації в завданнях із підрахунком (“грубим” або “тонким”). Основним спостереженням було наступне: в діапазоні 5-15 град відмічалися набагато більші зміни хвиль ВППП порівняно з такими в діапазоні 15-90 град. Амплітуда другого сенсорного компонента (Р2), латентні періоди обох сенсорних компонентів і даний параметр другого когнітивного компонента зростали із збільшенням складності завдання, тоді як амплітуди обох когнітивних компонентів N2/P3 зменшувалися. Крім того, невеликі зміни складності завдання впливали на концентрацію уваги і модулювали амплітуду N1 та латентний період Р2. Такі зміни ВППП розглядаються як електрографічні кореляти психофізіологічних даних, згідно з якими „мітка” активованого орієнтаційно селективного каналу є достатньою для „грубої” дискримінації, а додатковий процес розрахунків, забезпечуючий порівняння відповідей активованих каналів, робить можливою „тонку” дискримінацію.

\section{REFERENCES}

1. S. J. Luck and S. A. Hillyard, "Electrophysiological correlates of feature analysis during visual search," Psychophysiology, 31, No. 1, 291-308 (1994).

2. E. K. Vogel and S. J. Luck, "The visual N1 component as an index of a discrimination process," Psychophysiology, 37, No. 2, 190-203 (2000).

3. N. Lavie, "Perceptual load as a necessary condition for selective attention," J. Exp. Psychol. Human Percept. Perform., 21, No. 3, 451-468 (1995).

4. H. J. Heinze, S. J. Luck, G. R. Mangun, and S. A. Hillyard, "Visual event-related potentials index focused attention within bilateral stimulus arrays. I. Evidence for early selection," Electroencephalogr. Clin. Neurophysiol., 75, 511-527 (1990).

5. S. J. Luck, An Introduction to the Event-Related Potential Technique, MIT Press, Cambridge (2005).

6. J. B. Israel, G. L. Chesney, C. D. Wickens, and E. Donchin, "P300 and tracking difficulty: evidence for multiple resources in dual-task performance," Psychophysiology, 17, No. 3, 259-273 (1980).

7. J. Dushanova and D. Mitov, "Visual event-related potentials and orientation identification," C. R. Acad. Bulg. Sci., 65, No. 7, 969-976 (2012).

8. D. Urbach and H. Spitzer, "Attentional effort modulated by task difficulty,"Vis. Res. 35, No. 15, 2169-2177 (1995).

9. D. Urbach, The Correlation between Task Difficulty, Attentional Effort and Subject's Performance in Human Subjects, PhD Thesis, Tel-Aviv (2001).

10. Y. Chen, S. Martinez-Conde, S. L. Macknik, et al., "Task difficulty modulates the activity of specific neuronal populations in primary visual cortex," Nat. Neurosci., 11, No. 8, 974-982 (2008).

11. S. J. Luck, G. F. Woodman, and E. K. Vogel, "Eventrelated potential studies of attention," Trends Cogn. Sci., 4, No. 11, 432-440 (2000).

12. M. A. S. Boksem, T. F. Meijman, and M. M. Lorist, "Effects of mental fatigue on attention: An ERP study," Cogn. Brain Res., 25, 107-116 (2005).

13. J. R. Folstein and C. Van Petten, "Influence of cognitive control and mismatch on the N2 component of the ERP: a review," Psychophysiology, 45, No. 1, 152-170 (2008).

14. J. D. Wilder, E. Kowler, B. S. Schnitzer, et al., "Attention during active visual tasks: counting, pointing, or simply looking," Vis. Res., 49, No. 9, 1017-1031 (2009).

15. E. Donchin and M. G. H. Coles, "Is the P300 component a manifestation of context updating?" Behav. Brain Sci., 11, 357-374 (1988).

16. E. Donchin, W. Ritter, and W. C. McCallum, "Brain eventrelated potentials in man," in: Cognitive Psychophysiology: The Endogenous Components of the ERP, E. Callway, P. Tueting, and S. Koslow (eds.), Acad. Press, New York (1978), pp. 349-441.

17. S. A. Hillyard and M. Kutas, "Electrophysiology of cognitive processing," Annu. Rev. Psychol., 34, 33-61 (1983).

18. V. D. Glezer and A. A. Nevskaya, "Simultaneous and consecutive processing of information in the visual system," Dokl. Akad. Nauk SSSR, 155, 711-714 (1964).

19. V. D. Glezer, Vision and Mind, Erlbaum, Hillsdale (1995).

20. A.Vassilev, B. Simeonova, and M. Zlatkova, Information Processing in Visual System [in Russian], V. D. Glezer (ed.), Nauka, Leningrad (1982), pp. 35-40. 